\title{
Relating spatial pattern of forest cover to
}

\author{
accessibility
}

\section{$1 \quad 1$ Abstract}

2 Urban planning for optimal provision of recreational forests is not only con-

3 cerned with how much space is needed, but equally with how this could be

4 arranged in the landscape in order to make these forests accessible to many

5 potential visitors. The present study sought to establish relationships between

6 the spatial pattern of forest cover and these forests' accessibility - either on

7 foot or by bike - for short walks. This question was approached in an experi-

8 mental way using landscape structure metrics.

9 A factor analysis identified the common axes of spatial pattern. The first five

10 factors explained $82.2 \%$ of the variation of the original data set. The first

11 factor is related to forested area and number of forest patches, the second is

12 related to shape complexity. The third factor quantifies contiguity, and the

13 fourth measures the clumpiness of forests. The fifth refers to variability in 
1 forest shape. Only the factors related to forested area - shape complexity

2 and clumpiness - show a significant correlation with recreational provision. A

3 higher forest coverage and more forests should thus lead to a higher provision

4 for short walking trips. However, when a small afforestation budget is available,

5 high shape complexity, low forest contiguity and a high landscape shape index

6 (LSI) should take priority. Shape indices make the most important contribution

7 to single out patterns that offer recreation possibilities to a high number of

8 people. The findings show the potential of using landscape structure metrics

9 for modelling of forest recreational provision.

\section{Keywords}

11 landscape configuration, recreational provision, regional scale, landscape met12 rics

\section{${ }_{13} \quad 3$ Introduction}

${ }_{14}$ Over the $20^{\text {th }}$ century, large parts of the world have become strongly urbanized 15 and forests are increasingly recognized as vital elements for keeping urban 16 dwellers in touch with nature (Konijnendijk et al., 2005). In various countries 17 across Europe (e.g. United Kingdom, Denmark, the Netherlands, Belgium), 18 this has prompted decision makers to adopt ambitious policies for increasing 
1 the forest cover (Van Herzele et al., 2005).

2 Remarkably, these afforestation strategies - especially apparent in heavily ur-

3 banized regions of Western Europe - have shown to be particularly effective at

4 the national and regional scale (Van Herzele et al., 2005; Van Herzele, 2006).

5 To make valid projections of the outcome of such afforestation policies, their

6 effects on outdoor recreational provision should be evaluated. For this, the

7 wider scale - covering an area of several square kilometers - is being consid-

8 ered as the most appropriate (Zhang, 2004; Konijnendijk, 2004; Konijnendijk

9 and Randrup, 2004). Scaling up from a locus-based to a broader landscape

10 scale - which is further referred to as the regional scale - is likely to facilitate

11 the formulation of alternatives for recreation planning.

12 One of the few cases in which the effect of afforestation on recreational pro-

13 vision has been assessed on a regional scale is that of possible forest locations

14 near Antwerp, Belgium (Van Herzele et al., 2005). In this study, a GIS-based

15 working method was applied to evaluate seven alternative locations for the

16 creation of a new forest. Accessibility, defined as the number of people living

17 near enough to visit this future forest on a regular basis, was calculated using a

18 hierarchical system of standards, which links distance from the home to forest

19 size (Van Herzele and Wiedemann, 2003). The study used a fixed afforesta-

20 tion 'budget' of 300 ha, to be realized in one single forest unit. However, even

${ }_{21}$ the best location could supply the demand for forest recreation only partially.

22 This observation prompted a need for further research to verify whether a well 
1 considered spatial arrangement dividing the afforestation 'budget' in terms of

2 hectares over smaller units would benefit more urban dwellers. If so, a more

3 efficient solution could be obtained by creating spatial patterns that provide

4 a high number of people with short walking trips in relation to the land area

5 that is set aside for forest. The ability to quantify this pattern is a prerequisite

6 to monitor the recreational provision on a regional scale and offer alternative

7 scenarios for spatial planning.

8 In this paper, we aim to make a first step to establish relationships between

9 accessibility and measures of spatial pattern on a regional scale. Flanders

${ }_{10}$ (northern autonomous part of Belgium - 13,522 $\mathrm{km}^{2}$ ) is selected as study area,

11 as it features a very high degree of urbanization. According to UN (2004), 98

${ }_{12} \%$ of the flemish population is living in urban areas. This situation is combined

13 with a relatively low forest cover (about $11 \%$ ). Before elaborating on the case

14 study, we clarify the main concepts used, and their integration within the

15 study approach.

16 3.1 Recreational provision assessed by accessibility

17 Accessibility refers to the ability of using transportation facilities to reach 18 desired locations at suitable times (Geertman and Van Eck, 1995). Most mea19 sures of accessibility incorporate the distance between a person and his or her 20 destination, as well as the utility of this location. Some of the best known 
1 measures are based on the 'potential model' (Geertman and Van Eck, 1995;

2 Horner, 2004; Liu and Zhu, 2004; Stanilov, 2003; Talen and Anselin, 1998;

3 Zhang, 2004). The concept of potential is closely related to gravity, where

4 the attraction of object $a$ on object $b$ is directly related with the mass of

5 object $a$ and inversely related with the distance between these two objects.

6 Several software packages have implemented this concept, such as FlowMap

7 (http : //flowmap.geog.uu.nl), LADSS, and LocNet (Kammeier, 1999).

8 The potential model can be applied to recreation forests and calibrated using

9 data on average travel distance derived from socioeconomic research. Numer-

10 ous recreation studies in Flanders and elsewhere have concluded that travel

11 distance from home is the single most determinant factor for the use of a

12 recreational space (for an overview, see Van Herzele and Wiedemann (2003);

13 Grahn and Stigsdotter (2003) or Roovers et al. (2002)). In addition, the max-

14 imum distance people are willing to travel differs according to the attributes

15 of the recreational space. In this respect, the size of the forest is a determinant

16 factor for recreational use in terms of frequency, duration, and travel distance

17 (Van Herzele et al., 2005).

${ }_{18}$ 3.2 Relating spatial pattern of forest cover to accessibility

Landscape monitoring, focussing on spatial pattern, also defined as landscape

20 structure, rapidly evolved during the last decades, combining remote sensing 
1 and geographic information systems (GIS) (Forman and Godron, 1986; Turner

2 and Gardner, 1991; Farina, 2000; Luck and Wu, 2002; Turner et al., 2003).

3 Statistical measures to quantify composition and configuration of a landscape

4 are called landscape metrics or pattern indices (McGarigal and Marks, 1994).

5 In the field of landscape ecology, a comprehensive set of landscape indices has

6 been developed (Hulshoff, 1995; Riitters et al., 1995). These are considered as

7 useful tools to monitor the natural environment (Forman and Godron, 1986;

$8 \quad$ O’Neill et al., 1988; Baskent and Jordan, 1995; Trani and Giles, 1999; Farina,

9 2000; Imbernon and Branthomme, 2001). Metrics of landscape composition are

10 not spatially explicit. They measure what is present and their relative areal

11 proportions, without reference to its location in the landscape. Configuration

12 refers to the relative spatial arrangement of forests in the landscape (Turner

13 et al., 2001).

\section{${ }_{14} 4$ Research questions}

${ }_{15}$ The objective of this paper is to explore the relationship between the spatial

16 structure of a forested landscape, as assessed by pattern metrics, and the num-

17 ber of people that could use these forests for short walking trips, as determined

18 by accessibility. The following questions are answered:

19

(1) Which measures of spatial pattern are correlated with forest accessibility

20 on a regional scale? 
1 (2) Which of these metrics are independent of the amount of forest ?

2 (3) Which pattern metrics can single out forest patterns that contribute to

$3 \quad$ efficient land use, by providing the maximum number of people with forest

$4 \quad$ recreation, combined with the minimum land area set aside for forest ?

${ }_{5}$ This paper seeks to determine which metrics, if any, are most appropriate in 6 models assessing the provision of forest recreation on a regional scale.

\section{$7 \quad 5 \quad$ Material and Methods}

\section{$8 \quad 5.1$ Study Area}

9 The study area of Flanders (see figure 1) comprises $13,522 \mathrm{~km}^{2}$ and features 10 a modest forest cover $(146,000$ ha or ca. $11 \%$ forest cover) (Leyman and ${ }_{11}$ Vandekerkhove, 2003). High land pressure is caused, amongst others, by high 12 population density, amounting to 443 inhabitants per $\mathrm{km}^{2}$ (NIS, 2004).

13 [insert figure 1 here]

\section{$14 \quad 5.2$ Data and Software}

15 Artificial maps with random spatial patterns can be generated by random 16 processes (Turner et al., 2001). However, this technique is cumbersome, while 17 the existing spatial pattern of forest cover is readily available in digital format 
1 and performs better in capturing all pattern characteristics of actual landscape

2 patterns (Gustafson and Parker, 1992; Baldwin et al., 2004; Li and Wu, 2004).

3 To obtain a spectrum of spatial patterns, the forest map of Flanders (with a

4 spatial accuracy of $10 \mathrm{~m}$ (OC GIS-Vlaanderen, 2001a) was subdivided into 135

5 coverages corresponding to the geographic extent of equally sized hexagons,

6 as shown in figure 2. These hexagonal coverages were the basis for all pattern

7 metric calculations and were chosen as calculating units because of their reg-

8 ular and compact shape. These coverages were considered as just one possible

9 sample of future and past landscape patterns in Flanders.

10 Spatial population data was available per neighborhood, defined by the digital ${ }_{11}$ administrative boundaries of statistical sectors and was acquired from the 12 National Statistics Institute (NIS, 2001). Flanders counts 10,826 statistical 13 sectors. These are the size of a small number of building blocks and represent 14 a more or less homogeneous quarter in social respect (Pelfrene et al., 1998).

15 [insert figure 2 here]

16 Pattern metrics on a regional scale were determined for each hexagon, using 17 ESRI's ArcView 3.1 and Fragstats 3.3 (McGarigal and Marks, 1994). 


\section{$1 \quad 5.3$ Description of the GIS-based accessibility model}

2 To assess the accessibility of forested landscapes, the greenspace monitor-

3 ing tool was applied (Van Herzele and Wiedemann, 2003; Van Herzele et al.,

4 2005) and programmed in ArcView 3.1 using AVENUE. It is a straightfor-

5 ward method that determines the recreational provision in a region, using the

6 attractiveness of each greenspace, based on its size and specific attributes for

7 recreation. In this study, the tool was used in a simplified way, because extra

8 information concerning amenity was not available. We preferred this model

9 to other models, since it has been especially developed for the evaluation of 10 outdoor recreational provision.

11 The greenspace monitoring tool is based on the concept of accessibility as 12 developed by Geertman and Van Eck (1995). Attraction of each forest site is 13 linked to its area and expressed as a maximum distance people are willing to travel for a visit to this forest. This maximum distance delimits an attraction 15 zone, henceforth referred to as catchment. The recreational value of the forest 16 was expressed as the number of people living in the catchment. This relation17 ship (see Table 1) was based on the standards proposed by the Flemish forest 18 administration (Van Herzele et al., 2000). Mobility research in the Netherlands 19 has indicated that trips for leisure often cover short distances, and walking 20 and cycling are dominant modes of transport (Dieleman et al., 2002). To none 21 of the forests a distance larger than $5 \mathrm{~km}$ was allocated, which is considered 
1 the maximum distance that will be covered on foot or by bike (Van Herzele

2 et al., 2000; Dieleman et al., 2002).

3 [Insert Table 1 here]

4 For each forest fragment the attraction distance was calculated and the asso-

5 ciated catchment area was delineated. Per hexagon the area proportion within

6 a catchment was calculated. Each sector was consecutively clipped using the

7 catchment lines. The population of partial sectors was calculated using the

8 area proportion of the original statistical sector surface. The sum of all per-

9 sons having access to forest recreation was expressed as a percentage of the

10 population living within the hexagonal sample unit.

115.4 Description of the spatial pattern

12 To quantify the spatial pattern, 19 commonly used pattern indices were calcu13 lated (see Table 2). Landscape composition is described by the total forested 14 area (TA) and the number of forest patches (NP). Spatial configuration col15 lects different groups of metrics, referred to as contagion, patch-based metrics, 16 connectivity and proximity. The first, contagion of forest patches, is assessed 17 by the following metrics: PLADJ, DIVISION, MESH, SPLIT, AI.

18 [insert Table 2 here]

19 Patch-based metrics comprise a second group. Once area and perimeter of 
1 each forest are determined, these can be summarized (as in LSI) or frequency

2 distributions can be drafted. Shape complexity is quantified through PARA,

3 Shape, Frac, CONTig and Gyrate. Per sample unit the mean (.Mn) and

4 median value (.MD), as well as the standard deviation (.SD) and the coefficient

5 of variation (.CV) were recorded. Connectivity is assessed by LPI, CONNECT

6 and COHESION. Finally proximity - the degree to which patches are isolated -

7 is quantified using PROX and ENN.

8 Full description and calculation of these indices are provided by McGarigal 9 and Marks (1994) and Turner et al. (2001).

10 5.5 Relating spatial pattern of forest cover to accessibility

\section{$11 \quad$ 5.5.1 Correlation between accessibility and pattern metrics}

12 Using Spearman correlation analysis the correlation between accessibility and 13 each of the pattern metrics was tested for significance.

\section{5.5.2 Assessing independent groups of pattern metrics}

Using principle component analysis (PCA), the pattern metrics were grouped into a small number of independent components. In order to facilitate the 17 interpretation of the components, a Varimax rotation was applied. For a detailed description of this technique, we refer to Riitters et al. (1995). The PCA scores of all hexagons were then tested for correlation with the recreation ac- 
1 cessibility data from the GIS model, using a simple linear least square model

2 and Spearman rank correlation coefficient. This procedure was also adopted

3 by Honnay et al. (2003) to investigate the biological meaning of landscape

4 structure metrics, and determine which indices should be used in ecological

5 monitoring.

\section{5.5.3 Efficiency in recreational provision}

7 Discriminant analysis tests whether a set of variables (pattern metrics) is 8 able to correctly classify the hexagons into groups. The discriminating power 9 of the respective variables is relative to the coefficients of these variables in 10 the discriminant function (Mather, 1976; Buys, 2003). This technique was 11 applied to determine which metrics indicate differences between groups. It 12 requires a division of the hexagons into groups, according to their effectiveness ${ }_{13}$ in providing access to recreation.

To obtain these groups, the landscapes, representing the hexagons and their 15 spatial forest patterns, were ranked according to the criteria of optimization, 16 which are to maximize accessibility (Objective 2) with a minimum forest area 17 (Objective 1). According to pareto-logic, landscape $x$ is dominated by (or 18 worse than) landscape $y$ if landscape $y$ scores better on both objectives. For 19 this, landscape $y$ should have a higher accessibility, whilst containing a lower 20 - or equal - forest cover. In figure 3, a hypothetic example is given. Objective ${ }_{21} 2$, accessibility, should be maximized and objective 1, forest cover, should 
1 be minimized. Landscape $b$ is dominated by landscape $c$, since landscape $c$

2 has both a higher accessibility and a lower forest cover. Landscape $a$ scores

3 better on the first objective than landscape $b$, but scores worse on the second

4 objective. Landscapes $a$ and $b$ are considered not comparable, since neither

5 one dominates the other.

$6 \quad$ [Insert fig 3 here]

7 Dominated landscapes score worse on one of the two objectives, when com8 pared with at least one other landscape, while doing similar or worse for the 9 other objective. Non-dominated sample units form the so-called pareto-front 10 and represent land use configurations that cannot be improved for both ob11 jectives simultaneously. The forest patterns of these landscapes are given rank 12 "1". Rank "2" was assigned to hexagons that were dominated by only one 13 other landscape and rank "3" was given to all other sample units. The closer 14 a landscape is situated to the pareto-front, the more efficient the spatial forest 15 pattern is with respect to accessibility to recreation. These groups were used 16 to detect differences in landscape configuration, regardless of the percentage 17 of forest cover. 
$2 \quad 6.1$ Correlation between pattern metrics and accessibility

3 In Table 3, Spearman correlations between accessibility and pattern metrics

4 are listed. Not surprisingly, accessibility is highly correlated with forest com5 position, described by TA $(r=0.91)$ and NP $(r=0.75)$. Contagion and connec6 tivity have an intermediate influence on accessibility; the highest correlation 7 in this group is with MESH $(r=0.66)$. Regarding distribution of forest size, 8 it is the variation ( $r=0.65$ for AREA.CV and $r=0.64$ for AREA.SD), which 9 is correlated. In the group describing the distribution of forest shape, several 10 metrics have a significant correlation with accessibility, although none of these 11 is high. The summarizing LSI is nonetheless rather well correlated $(r=0.72)$. 12 Finally, forest isolation, quantified by ENN.MN and ENN.SD, is negatively cor13 related with accessibility ( $r=-0.79$ for ENN.MN; $r=-0.81$ for ENN.SD).

${ }_{14}$ [Insert Table 3 here]

\subsection{Distinguishing configuration from composition}

${ }_{16}$ Principal component analysis shows that the first 5 components explain $82,2 \%$ 17 of the original data set. In Table 4, the factor loadings are listed, expressing the 18 correlation between a factor and the original variables after Varimax rotation. 
1 Each variable is assigned to the factor for which the correlation is highest.

2 The pattern metrics are ranked according to decreasing correlation.

3 Clearly, the factors in landscape pattern in Flanders do not completely coincide

4 with the pattern aspects as defined by Turner et al. (2001). The first factor is

5 highly correlated with AREA.SD, Prox.SD, GYRATE.CV, MESh, Prox.Mn,

6 AREa.CV, Gyrate.sD, Ta, COhesion, AREa.mn, Pladj, Ai, Prox.mD and

7 SHAPE.CV. These variables are strongly determined by the total area of forest

8 cover.

$9 \quad$ Insert Table 4 here]

10 Variables associated with the second factor are: SHAPE.MN, FRAC.MN, SHAPE-

11 .MD, GYRATE.MD, FRAC.MD, GYRATE.MN, AREA.MD, SHAPE.SD, FRAC.SD

12 AND ENN.CV. These are all indices that describe patch shape. As the values

13 of these indices increase, the patches become more irregular in shape.

${ }_{14}$ The third factor can be interpreted as a supplementary factor connected with 15 forest shape, since it is correlated with CONTIG.MN, PARA.Mn, CONTIG.MD, 16 PARA.MD, AI and FRAC.CV . The factor has its highest, albeit negative, cor17 relation $(-0.81)$ with CONTIG.MN. This pattern index assesses the spatial 18 connectedness of a patch, which is related to both patch size and patch shape.

19 The fourth factor can be interpreted as a component measuring the clumpiness 20 of the landscape. Variables correlated with this factor are: LSI, DIVISION, LPI, 
1 NP, SPLIT, ENN.SD, ENN.Mn, CONNECT, ENN.MD and PROX.CV. The number

2 of patches, their size and geographical distribution have an important influence

3 on these indices. Many indices using the distances between two neighboring

4 forest patches are linked to this factor.

5 Since the fifth factor contains solely standard deviations and coefficients of

6 variation of shape indices, it is interpreted as a factor describing variability

7 of shape complexity. Correlated indices are: CONTIG.SD, PARA.CV, PARA.SD

8 and CONTIG.CV.

9 Table 5 shows the Spearman correlations between the forest accessibility and

10 the pattern indices that are selected for their high correlation with the respec-

11 tive factors. The aspects of landscape configuration which are important for 12 accessibility, are described by AREA.SD (0.64), SHAPE.MN (0.29), CONTIG.MN

13 (0.03), LSI (0.72) and CONTIG.SD (0.16). Correlation with the first factor is 14 meaningful, as was expected. From the other factors, only the fourth one (LSI)

15 yields a correlation coefficient that can be considered important.

\subsection{Efficiency in recreational provision}

${ }_{17}$ For the discriminant analysis, we use the three groups as obtained from pareto18 ranking. Group 1 contains non-dominated landscapes; the hexagons in group 192 are dominated by only 1 other landscape, and all other landscapes are in 20 group 3. 
1 During a discriminant analysis, a multiple ANOVA is performed, testing for

2 the equality of means of the indicated groups. The value of Wilks Lambda

$30.1750(\mathrm{p}=0.00)$ indicates that the groups are separable on the basis of the

4 values of the pattern indices. The pairwise comparison in Table 6 shows sig-

5 nificant differences in the multivariate means of all three groups.

$6 \quad$ Insert Table 6]

7 A univariate ANOVA is performed. Significant univariate differences are record8 ed between group 1 and 3 for the following variables: GYRATE.MD, ENN.MN 9 and ENN.MD. Groups 2 and 3 are significantly different regarding FRAC.SD and 10 FRAC.CV. None of the univariate means were statistically different for groups ${ }_{11} 1$ and 2. None of the variables, associated with the factors of forest pattern, as 12 determined in section 6.2, are significantly different for the three groups. Only 13 a few pattern indices feature a significant difference for the specified groups. 14 Hence, the results are not shown here.

${ }_{15}$ Two discriminant functions are drawn. The canonical coefficients of these dis16 criminant functions can be found in Table 7 . These are sorted according to 17 decreasing coefficients. For the first discrimination function, FRAC.MN, CON18 TIG.SD, FRAC.SD and CONTIG.MN have high coefficients. The coefficients for 19 the other pattern metrics quickly drop to zero. In the second discriminant 20 function, FRAC.SD and CONTIG.SD obtain rather high coefficient values as well. 21 CONTIG.SD and CONTIG.MN also describe main aspects of landscape pattern 
1 (cfr. section 6.2) and are not directly correlated with forest accessibility. As is

2 apparent from Table 4, FRAC.MN is correlated (0.89) with the second factor of

3 forest pattern, and can be regarded as more or less equivalent to SHAPE.MN.

$4 \quad$ FRAC.SD is not very well correlated with the factors of landscape pattern (0.60

5 for the second factor).

6 When performing a cross-validation through iteration, each observation is 7 systematically dropped, the discriminant function is re-estimated, and the 8 excluded observation is classified. This leave-one-out technique reports a clas9 sification error of $14.93 \%$. Keeping in mind that the results are only used for 10 the detection of differences between groups and not for absolute prediction of 11 which group a landscape will belong to, this error is considered acceptable.

\section{${ }_{12} \quad 7 \quad$ Discussion and Conclusions}

Urban planning for optimal provision of recreational forests is not only concerned with how much space is needed, but equally with how this could be spatially arranged in the landscape in order to make these forests accessible to many potential visitors. In this context, the present study sought to establish significant relationships between the spatial pattern of forest cover and forest accessibility for short walks.

19 The main originality of the study resides in the use of landscape structure metrics in the context of recreation planning. Existing research into spatial 
1 structure predominantly focuses on the use of pattern metrics for ecological 2 monitoring (e.g. Honnay et al. (2003)). More specifically, the goal of this paper

3 was to determine the utility of a given set of pattern metrics in planning for 4 the creation of new forests.

5 Given the experimental nature of the study, the results are valuable as prac6 tical knowledge for the construction of models for recreation assessment. The 7 results show that accessibility for short walks is related to the spatial pattern 8 of forest cover. First and foremost, forested area and the number of forests 9 have an effect on the provision of forests for short walks. The correlation is 10 respectively 0.91 and 0.75 . Metrics describing forest connectivity and forest 11 shape have a lower influence on accessibility and a negative correlation is found 12 between accessibility and forest isolation. These correlations between accessibility and pattern metrics indicate that nearly all aspects of spatial pattern 14 have an influence on the recreational provision under investigation. Moreover, 15 high correlation amongst pattern metrics suggest that when metrics are se16 lected only on the criterion of high correlation with accessibility, the selected 17 subset would provide redundant information. Factor analysis, commonly performed for the selection of a subset of pattern metrics, yields five factors of spatial pattern. The first factor is related to 20 forested area; the second factor indicates shape complexity of forest patches. ${ }_{21}$ The third factor quantifies contiguity. The fourth factor measures the clumpi22 ness of forests. The fifth factor contains metrics referring to variability in 
1 forest shape. Only the first, the second and the fourth factor have a signifi-

2 cant correlation with recreational provision. The correlation coefficient with

3 the second factor is low but still significant. Contagion, expressed by MESH,

4 seems to be a useful pattern metric based on its correlation with accessibility.

5 Factor analysis, however, indicates that this metric describes the same compo-

6 nent of spatial pattern as expressed by forested area or patch size distribution.

7 Similarly, an increasing number of forest patches entails a decreasing forest

8 isolation. Only forest contiguity, making up 2 of the 5 factors of the spatial

9 pattern, is not significantly correlated with recreational provision.

${ }_{10}$ This leads to the logical conclusion that a higher forest coverage and more 11 forests will indeed increase recreational provision. However, when a small af12 forestation budget is available, high shape complexity, low forest contiguity 13 and a high landscape shape index (LSI) warrant special attention.

${ }_{14}$ To corroborate these conclusions, the forest patterns available were divided 15 into groups. To ensure that the groups were not dependent on the quantity of 16 forested area, pareto logic was used. Univariate ANOVA showed that metrics 17 having different means for the defined groups are variables related to for18 est shape (GYRATE.MN, FRAC.SD and FRAC.CV) and isolation (ENN.MN and 19 ENN.MD). These variables show a significant Pearson correlation with accessi20 bility. They are allotted to the first, second and fourth factor in the PCA, but 21 do not show a very high correlation with their respective factor. 
1 Consequently, a discriminant analysis was performed on these groups. The 2 results show that the pattern metrics are able to classify the forest configu3 rations into the given groups with an accuracy of $85.07 \%$, based on shape 4 indices alone (FRAC.MN, FRAC.SD, CONTIG.MN and CONTIG.SD). These vari5 ables are not correlated with accessibility, but show high correlations with the 6 factors two, three and five. Despite the small divergence in outcome between 7 the factor analysis and discriminant analysis, this analysis confirms the impor8 tance of shape and contiguity when a higher recreational provision is sought 9 without a substantial enlargement of the forested area.

10 The findings of this study confirm that possibilities exist for the use of pattern 11 metrics in the modelling of forest recreation. At the same time it indicates is12 sues for further investigation. First and foremost, the relationships between 13 spatial pattern and recreational provision should be verified in other geograph14 ical regions. Secondly, it should be tested whether these relations equally apply 15 to longer forest recreation (e.g. hiking, ..), where accessibility by car is more 16 important.

${ }_{17}$ Finally, models for recreational provision, based on pattern metrics, should be developed. The following variables are assumed to yield good results for short forest recreation : forested area, number of forest features, shape metrics 20 such as fractal dimension (FRAC) or contiguity (CONTIG) and nearest neighbor distances (ENN). Since the relationships between pattern metrics and species 22 richness have been studied intensively, other objectives - such as maximizing 
1 biodiversity - and ancillary data - such as road networks - can be included in

2 the model.

\section{$3 \quad 8$ Acknowledgements}

4 The authors would like to express their gratitude towards the colleagues in

5 the Laboratory for Forest Management and Spatial Information Techniques,

6 Department of Forest and Water Management in the University of Ghent. We

7 would like to thank the anonymous reviewers for their constructive remarks.

8 References

9 Baldwin, D. J. B., Weaver, K., Schnekenburger, F., Perera, A., 2004. Sensi-

10 tivity of landscape pattern indices to input data characteristics on real land-

${ }_{11}$ scapes: implications for their use in natural disturbance emulation. Land-

12 scape Ecol., 19, 255-271.

13 Baskent, E., Jordan, G., 1995. Characterizing spatial structure of forest land-

$14 \quad$ scapes. Can. J. Forest Res., 25, 1830-1849.

15 Buys, A., 2003. Applied Statistics (Stenfert Kroese, Groningen).

16 Dieleman, F., Dijst, M., Burghouwt, G., 2002. Urban form and travel behav-

17 iour: Microlevel household attributes and residential context. Urban Studies,

$18 \quad 39,507-525$. 
1 Farina, A., 2000. Principles and Methods in Landscape Ecology (Kluwer Aca-

2 demic Publishers, Dordrecht, Netherlands).

3 Forman, R., Godron, M., 1986. Landscape Ecology (John Wiley and Sons,

$4 \quad$ New York).

${ }_{5}$ Geertman, S. C. M., Van Eck, J. R. R., 1995. GIS and models of accessibility

6 potential: an application in planning. Int. J. of Geogr. Inf. Sc., 9, $67-80$.

7 Grahn, P., Stigsdotter, U., 2003. Landscape planning and stress. Urban For. Urban Green., 2, 1-18.

9 Gustafson, E., Parker, G., 1992. Relationships between land cover proportion 10 and indices of landscape spatial pattern. Landscape Ecol., 7, 101-110.

11 Honnay, O., Piessens, K., Van Landuyt, W., Hermy, M., Gulinck, H., 2003.

12 Satellite based land use and landscape complexity indices as predictors for 13 regional plant species diversity. Landsc. Urban Plan., 63, 241-250.

Konijnendijk, C., 2004. Enhancing the forest science policy interface in europe: 
Urban forestry showing the way. Scand. J. Forest Res., 19, 123-128.

2 Konijnendijk, C., Nilsson, K., Randrup, T., Schipperijn, J., editors, 2005.

$3 \quad$ Urban forests and trees: a reference book (Springer, Berlin Heidelberg).

4 Konijnendijk, C. C., Randrup, R. B., 2004. Encyclopedia of Forest Sciences,

$5 \quad$ chap. Landscape and Planning: Urban forestry. 1st edn. (Elsevier Academic

$6 \quad$ Press), pp. 471-478.

7 Leyman, A., Vandekerkhove, K., 2003. Oppervlakte bos in Vlaanderen die is

$8 \quad$ opgenomen in verschillende beschermingsstatuten : enkele statistieken. Silva

$9 \quad$ Belgica, 110, $32-37$.

10 Li, H., Wu, J., 2004. Use and misuse of landscape indices. Landscape Ecol., $11 \quad \mathbf{1 9}, 389-399$.

12 Liu, S., Zhu, X., 2004. Accessibility analyst: an integrated GIS tool for acces-

13 sibility analysis in urban transportation planning. Environ. Plan. B-Plan.

$14 \quad$ Des., 31, 105-124.

15 Luck, M., Wu, J., 2002. A gradient analysis of urban landscape pattern: a 16 case study from the Phoenix Metropolitan Region, Arizona, USA. Landscape $17 \quad$ Ecol., 17, 327-339.

18 Mather, P. M., 1976. Computational methodes of multivariate analysis in phys19 ical geography (John Wiley \& Sons, Londen, UK).

20 McGarigal, K., Marks, B., 1994. FRAGSTATS: Spatial Pattern Analysis Pro${ }_{21}$ gram for Quantifying Landscape Structure. Version 2 (Forest Science De22 partment, Origon State University, Carvallis.).

23 NIS, 2001. Demographic population data per statistical sector. National In- 
stitute of Statistics, Brussels, Belgium.

2 NIS, 2004. Rijksregister, bevolkingsdichtheid per gewest, 1990-2003. URL http://aps.vlaanderen.be/sgml/reeksen/1559.htm (last access date 29-08-2005)

5 OC GIS-Vlaanderen, 2001a. Digital version of the forest mapping, MVG, LIN, AMINAL, department Bos \& Groen, OC GIS-Vlaanderen. URL http://www.gisvlaanderen.be (last access date 29-08-2005).

\& O’Neill, R., Krummel, J., Gardner, R., Sugihara, G., Jackson, B., DeAn9 gelis, D., Milne, B., Turner, M., Zygmunt, B., Christensen, S., Dale, ${ }_{10}$ V., Graham, R., 1988. Indices of landscape pattern. Landscape Ecol., 1, $11 \quad 153-162$.

12 Pelfrene, E., Bleyen, L., Backer, G. D., 1998. Uptake in breast cancer screen13 ing - a sociogeographical analysis. Eur. J. Public Health, 8, 146-149. and structure metrics. Landscape Ecol., 10, 23-39.

17 Roovers, P., Hermy, M., Gulinck, H., 2002. Visitor profile, perceptions and 18 expectations in forests from a gradient of increasing urbanisation in central $19 \quad$ Belgium. Landsc. Urban Plan., 59, 129-145.

20 Stanilov, K., 2003. Accessibility and land use: The case of suburban Seattle, 1960-1990. Reg. Stud., 37, 783-794.

${ }_{22}$ Talen, E., Anselin, L., 1998. Assessing spatial equity: an evaluation of mea- 
1 sures of accessibility to public playgrounds. Environ. Plan. A, 30, 595-613.

2 Trani, M., Giles, R., 1999. An analysis of deforestation: Metrics used to de-

$3 \quad$ scribe pattern change. For. Ecol. and Manage., 114, 459-470.

4 Turner, M., Pearson, S., Bolstad, P., Wear, D., 2003. Effects of land cover

5 change on spatial pattern of forest communities in the Southern Appalachian

$6 \quad$ Mountains (USA). Landscape Ecol., 18, 449-464.

7 Turner, M. G., Gardner, R., 1991. Quantitative methods in landscape ecol-

8 ogy, chap. Quantitative methods in landscape ecology: An Introduction

$9 \quad$ (Springer-Verlag), pp. 3-14.

${ }_{10}$ Turner, M. G., Gardner, R. H., ONeill, R. V., 2001. Landscape ecology. In 11 theory and practice. Pattern and process. (Springer-Verlag, New York).

12 UN, 2004. World urbanization prospects: the 2003 revision. , United Nations,

$13 \quad$ New York.

14 Van Herzele, A., 2006. A forest for each city and town: story lines in the policy

15 debate for urban forests in Flanders. Urban Studies, 43, 673-696.

Van Herzele, A., De Clercq, E. M., Wiedemann, T., 2005. Strategic planning

${ }_{17}$ for new forests in the urban periphery: Through the lens of social inclusiveness. Urban For. Urban Green., 3, 177-188. Van Herzele, A., Wiedemann, T., 2003. A monitoring tool for the provision 20 of accessible and attractive urban green spaces. Landsc. Urban Plan., 63, 21 $109-126$.

${ }_{22}$ Van Herzele, A., Wiedemann, T., Van Overmeiren, M., 2000. Environment 23 and Nature Report for Flanders MIRA-S 2000, chap. Stedelijk Milieu (Ur- 
1 ban Environment) (Vlaamse Milieumaatschappij \& Garant Uitgevers NV, 2 Leuven/Apeldoorn).

3 Zhang, M., 2004. Exploring the relationship between urban form and nonwork $4 \quad$ travel through time use analysis. Landsc. Urban Plan., 73, 244-261. 


\section{Tables}

Table 1

Relation between the minimum area of forest and the maximum distance that will be covered for a recreation experience (after Van Herzele et al., 2000)

\begin{tabular}{|c|c|}
\hline Maximum distance (m) & Minimal area (ha) \\
\hline 150 & - \\
400 & 1 \\
800 & 10 \\
1600 & 30 \\
3200 & 60 \\
5000 & 200 \\
\hline
\end{tabular}


Table 2

Acronyms of the pattern metrics

\begin{tabular}{|c|c|}
\hline Abbreviation & Full name (units) \\
\hline. $\mathrm{MN}$ & mean value of the preceding pattern index \\
\hline. $\mathrm{MD}$ & median value of the preceding pattern index \\
\hline. $\mathrm{SD}$ & standard deviation of the preceding pattern index \\
\hline. $\mathrm{CV}$ & coefficient of variation of the preceding pattern index \\
\hline $\mathrm{TA}$ & Total Area (ha) \\
\hline NP & Number of Patches (-) \\
\hline PLADJ & Percentage of Like Adjacencies (\%) \\
\hline DIVISION & Landscape Division Index (Proportion) \\
\hline MESH & Effective Mesh Size (ha) \\
\hline SPLIT & Splitting Index (-) \\
\hline AI & Aggregation Index $(\%)$ \\
\hline LSI & Landscape Shape Index (-) \\
\hline AREA & Area (ha) \\
\hline PARA & Perimeter-Area Ratio (-) \\
\hline SHAPE & Shape Index (-) \\
\hline FRAC & Fractal Dimension Index (-) \\
\hline CONTIG & Contiguity Index (-) \\
\hline GYRATE & Radius of Gyration (m) \\
\hline LPI & Largest Patch Index (\%) \\
\hline CONNECT & Connectance Index (\%) \\
\hline COHESION & Patch Cohesion Index (-) \\
\hline PROX & Proximity Index (-) \\
\hline $\mathrm{ENN}$ & Euclidean Nearest-Neighbor Distance (m) \\
\hline
\end{tabular}


Table 3

Spearman correlations between accessibility and the pattern metrics

* $0.01<P \leq 0.05 ;{ }^{* *} P \leq 0.01$

\begin{tabular}{|r|l|rl|}
\hline Aspect & Metric & $\mathrm{r}$ & \\
\hline composition & TA & 0.91 & $* *$ \\
composition & NP & 0.75 & $* *$ \\
contagion & DIVISION & 0.17 & \\
contagion & MESH & 0.66 & $* *$ \\
contagion & SPLIT & 0.17 & \\
contagion & AI & 0.43 & $* *$ \\
contagion & PLADJ & 0.51 & $* *$ \\
connectivity & LPI & -0.15 & \\
connectivity & CONNECT & -0.45 & $* *$ \\
connectivity & COHESION & 0.47 & $* *$ \\
patch size distribution & AREA.MN & 0.54 & $* *$ \\
patch size distribution & AREA.MD & 0.10 & \\
patch size distribution & AREA.SD & 0.64 & $* *$ \\
patch size distribution & AREA.CV & 0.65 & $* *$ \\
patch based configuration & LSI & 0.72 & $* *$ \\
patch shape & SHAPE.MN & 0.29 & $* *$ \\
patch shape & SHAPE.MD & 0.08 & \\
patch shape & SHAPE.SD & 0.37 & $* *$ \\
patch shape & SHAPE.CV & 0.38 & $* *$ \\
patch shape & FRAC.MN & 0.14 & \\
patch shape & FRAC.MD & 0.19 & \\
patch shape & FRAC.SD & 0.20 & \\
patch shape & FRAC.CV & 0.21 & $*$ \\
patch shape & PARA.MN & -0.04 & \\
patch shape & PARA.MD & -0.06 & \\
patch shape & PARA.SD & 0.16 & \\
patch shape & PARA.CV & 0.21 & $*$ \\
patch shape & CONTIG.MN & 0.03 & \\
patch shape & CONTIG.MD & 0.18 & \\
patch shape & CONTIG.SD & 0.16 & \\
patch shape & CONTIG.CV & 0.15 & \\
patch shape & GYRATE.MN & 0.32 & $* *$ \\
patch shape & GYRATE.MD & 0.11 & \\
patch shape & GYRATE.SD & 0.48 & $* *$ \\
patch shape & GYRATE.CV & 0.52 & $* *$ \\
patch isolation & PROX.MN & 0.67 & $* *$ \\
patch isolation & PROX.MD & 0.80 & $* *$ \\
patch isolation & PROX.SD & 0.66 & $* *$ \\
patch isolation & PROX.CV & 0.01 & \\
patch isolation & ENN.MN & -0.79 & $* *$ \\
patch isolation & ENN.MD & -0.63 & $* *$ \\
patch isolation & ENN.SD & -0.81 & $* *$ \\
patch isolation & ENN.CV & -0.33 & $* *$ \\
\hline
\end{tabular}


Table 4

Factor loadings for the factors after VARIMAX rotation

The first 5 factors explain $82 \%$ of the variance of the original data set

\begin{tabular}{|c|c|c|}
\hline Factor & Pattern metrics & $\mathrm{r}$ \\
\hline 1 & AREA.SD & 0.94 \\
1 & PROX.SD & 0.90 \\
1 & GYRATE.CV & 0.90 \\
1 & MESH & 0.90 \\
1 & PROX.MN & 0.87 \\
1 & AREA.CV & 0.87 \\
1 & GYRATE.SD & 0.86 \\
1 & TA & 0.83 \\
1 & COHESION & 0.76 \\
1 & AREA.MN & 0.74 \\
1 & PLADJ & 0.68 \\
1 & PROX.MN & 0.62 \\
1 & SHAPE.CV & 0.57 \\
\hline 2 & SHAPE.MN & 0.93 \\
2 & FRAC.MN & 0.89 \\
2 & SHAPE.MD & 0.88 \\
2 & GYRATE.MD & 0.82 \\
2 & FRAC.MD & 0.80 \\
2 & GYRATE.MN & 0.78 \\
2 & AREA.MD & 0.65 \\
2 & SHAPE.SD & 0.61 \\
2 & FRAC.SD & 0.60 \\
2 & ENN.CV & 0.31 \\
\hline 3 & CONTIG.MN & -0.81 \\
3 & PARA.MN & 0.78 \\
3 & CONTIG.MD & -0.74 \\
3 & PARA.MD & 0.73 \\
3 & AI & -0.67 \\
3 & FRAC.CV & 0.59 \\
\hline 4 & LSI & 0.91 \\
4 & DIVISION & 0.84 \\
4 & LPI & -0.82 \\
4 & NP & 0.81 \\
4 & SPLIT & 0.66 \\
4 & ENN.SD & -0.65 \\
4 & ENN.MN & -0.60 \\
4 & CONNECT & -0.56 \\
4 & ENN.MD & -0.37 \\
4 & PROX.CV & 0.29 \\
\hline 5 & CONTIG.SD & 0.95 \\
5 & PARA.CV & 0.95 \\
5 & PARA.SD & 0.95 \\
5 & CONTIG.CV & 0.93 \\
\hline & & \\
\hline
\end{tabular}


Table 5

Spearman correlation coefficients between the selected variable representing a factor and forest accessibility

\begin{tabular}{|c|c|l|}
\hline Factor & Variable & $\mathrm{r}$ \\
\hline F1 & AREA.SD & $0.64 * *$ \\
F2 & SHAPE.MN & $0.29^{* *}$ \\
F3 & CONTIG.MN & 0.03 \\
F4 & LSI & $0.72 * *$ \\
F5 & CONTIG.SD & 0.16 \\
\hline
\end{tabular}


Table 6

Multiple ANOVA for the three groups

\begin{tabular}{|c|c|c|c|c|}
\hline & $\mathrm{F}$ & $\mathrm{df1}$ & $\mathrm{df2}$ & $\mathrm{p}$ \\
\hline \multicolumn{5}{|c|}{ Wilks lambda } \\
\hline 0.175 & 2.721 & 88 & 176 & $0.00^{*}$ \\
\hline \multicolumn{5}{|c|}{ Hotelling's T pairwise comparison } \\
\hline $1-2$ & 3.142 & 44 & 88 & $0.00^{*}$ \\
$1-3$ & 2.612 & 44 & 88 & $0.00^{*}$ \\
$2-3$ & 2.926 & 44 & 88 & $0.00^{*}$ \\
\hline
\end{tabular}


Table 7

Canonic coefficients for the two discriminant functions

\begin{tabular}{|c|c|c|}
\hline Pattern metric & First discriminant function & Second discriminant function \\
\hline FRAC.SD & 326.07 & -2171.81 \\
\hline CONTIG.SD & 369.88 & 1154.52 \\
\hline FRAC.MN & -592.17 & -103.27 \\
\hline CONTIG.MN & 300.09 & -223.58 \\
\hline FRAC.MD & 90.36 & -67.19 \\
\hline SHAPE.MN & 45.86 & 27.37 \\
\hline SHAPE.SD & -38.76 & 5.22 \\
\hline FRAC.CV & -2.70 & 22.59 \\
\hline CONTIG.MD & -17.19 & 2.98 \\
\hline PLADJ & -5.83 & 8.99 \\
\hline AI & 3.45 & -9.86 \\
\hline CONTIG.CV & -1.92 & -9.06 \\
\hline SHAPE.MD & -4.54 & 5.39 \\
\hline DIVISION & -2.01 & 0.90 \\
\hline COHESION & 1.65 & -0.05 \\
\hline AREA.MD & 0.75 & 0.94 \\
\hline PARA.CV & -0.39 & -0.45 \\
\hline SHAPE.CV & 0.42 & -0.25 \\
\hline CONNECT & -0.17 & 0.17 \\
\hline PD & -0.21 & -0.05 \\
\hline LSI & -0.10 & -0.12 \\
\hline AREA.SD & 0.16 & 0.05 \\
\hline AREA.MN & -0.15 & 0.04 \\
\hline GYRATE.MN & 0.08 & -0.05 \\
\hline PARA.MN & 0.08 & -0.05 \\
\hline GYRATE.MD & -0.08 & 0.01 \\
\hline PARA.SD & 0.02 & 0.06 \\
\hline GYRATE.SD & -0.02 & -0.03 \\
\hline GYRATE.CV & 0.00 & 0.05 \\
\hline LPI & 0.00 & 0.04 \\
\hline SPLIT & -0.01 & -0.03 \\
\hline AREA.CV & -0.01 & -0.01 \\
\hline ENN.CV & 0.02 & 0.00 \\
\hline ENN.MD & -0.01 & 0.01 \\
\hline ENN.SD & 0.00 & 0.01 \\
\hline NP & 0.00 & 0.01 \\
\hline MESH & 0.00 & -0.01 \\
\hline PROX.MD & 0.00 & -0.01 \\
\hline PARA.MD & 0.00 & 0.00 \\
\hline ENN.MN & 0.00 & 0.00 \\
\hline PROX.CV & 0.00 & 0.00 \\
\hline PROX.MN & 0.00 & 0.00 \\
\hline PROX.SD & 0.00 & 0.00 \\
\hline TA & 0.00 & 0.00 \\
\hline
\end{tabular}




\section{$1 \quad 10 \quad$ Figure captions}

2 Figure 1 : Location of the study area in Belgium

3 Figure 2: The Flanders region of Belgium overlayed with the hexagons used

4 as sample units

5 The grey shades are forests.

6 Figure 3: Illustration of the pareto-rank logic

7 Landscape $b$ is dominated by landscape $c$, since landscape $c$ has both a lower

8 value for objective one (that should be minimized) and a higher value for ob9 jective two (that should be maximized).

10 Landscape $a$ scores better on the first objective than landscape $b$, but scores

11 worse on the second objective. Landscapes $a$ and $b$ are considered not com12 parable, since neither one dominates the other.

$13 \quad 11 \quad$ Figures

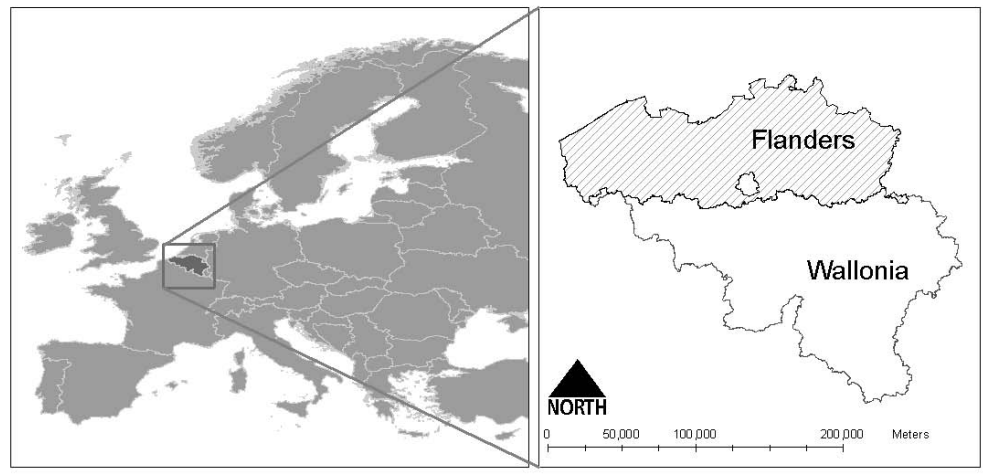

Fig. 1. 


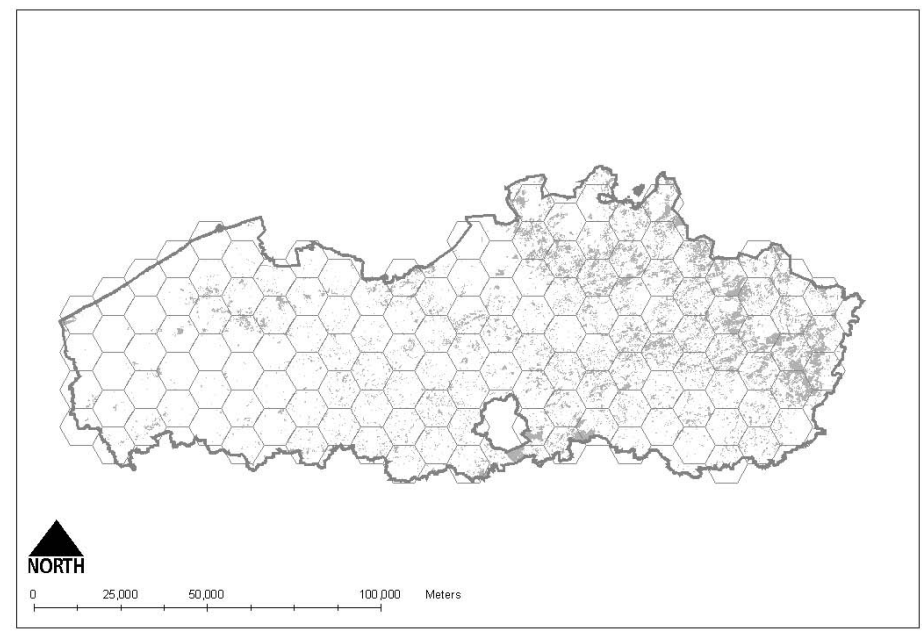

Fig. 2. 


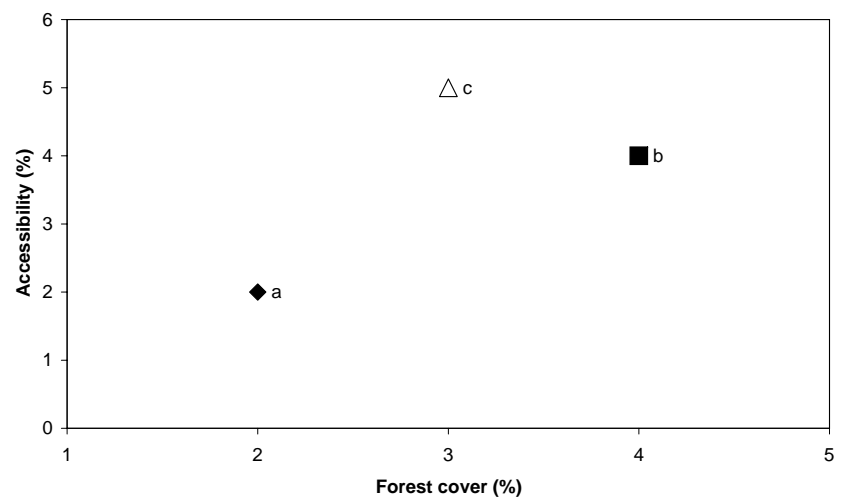

Fig. 3 . 